\title{
Simulasi Perambatan Cahaya pada Biomaterial dengan Kandungan Zat Pewarna Menggunakan Metode Elemen Hingga
}

\author{
Vebi Nadhira ${ }^{1, *}$, Deddy Kurniadi ${ }^{1}$, Agah D. Garnadi ${ }^{2}$ dan E. Juliastuti ${ }^{1}$ \\ ${ }^{1}$ Kelompok Keahlian Instrumentasi dan Kontrol, Fakultas Teknologi Industri \\ Institut Teknologi Bandung, Ganesha 1040132 Bandung Indonesia \\ ${ }^{2}$ Departemen Matematika, Fakultas Matematika dan Ilmu Pengetahuan Alam \\ Institut Pertanian Bogor, Jl Meranti, Kampus Darmaga, Bogor 16680, Indonesia \\ *Email : vebi@tf.itb.ac.id
}

\begin{abstract}
Abstrak. Salah satu metode untuk memperoleh citra penampang melintang buah adalah dengan memanfaatkan teknik Diffuse Optical Tomography (DOT atau tomografi difusi optik), dimana cahaya yang ditembakan pada objek akan dihamburkan dan ditransmisikan melalui objek (cahaya eksitasi). Hampir semua jenis buah mengandung zat pewarna (dyes) yang bersifat fluoresen (kbbi: mempunyai sifat dapat memancarkan cahaya yg gelombangnya lebih panjang daripada cahaya datang). Berdasarkan kandungan zat pewarna yang bersifat fluoresen pada buah, maka pada kondisi real, cahaya yang ditembakan pada objek akan mengalami 2 peristiwa, yaitu dihamburkan dan ditransmisikan melalui objek (cahaya eksitasi) serta diserap oleh fluoresens (zat pewarna) dan kemudian diemisikan kembali (cahaya emisi). Cahaya emisi tersebut mampu menambah informasi dari kondisi objek. Untuk mengidentifikasi efek zat pewarna pada buah terhadap sensitifitas citra penampang melintang buah berbasis Fluoresens DOT (FDOT), maka diperlukan simulasi numerik perambatan cahaya pada buah. Pada simulasi ini digunakan metode elemen hingga (MEH). Selain itu, penggunaan pendekatan cahaya total (cahaya eksitasi dan emisi) digunakan untuk menghindari perhitungan yang tidak efisien (perhitungan informasi koefisien optik objek dari cahaya eksitasi dan emisi secara terpisah). Hasil simulasi numerik menunjukan bahwa perhitungann cahaya emisi zat pewarna buah mampu meningkatkan sensitifitas citra penampang melintang buah.
\end{abstract}

Kata kunci: Perambatan Cahaya, Biomaterial, Zat Pewarna, Metode Elemen Hingga

\section{PENDAHULUAN}

Diffuse Optical Tomography (DOT atau tomografi difusi optik) merupakan salah satu metode untuk mencitrakan penampang bagian dalam suatu objek. Saat ini, perangkat tomografi yang umum digunakan diantaranya adalah CT-scan (computed x-ray tomography), USG (ultrasonography), MRI (Magnetic Resonance Imaging) atau PET (Positron Emission Tomography). Tomografi itu sendiri diartikan sebagai pencitraan penampang lintang atau irisan (slice) suatu objek berdasarkan data pengukuran pada bidang batas atau proyeksi objek baik dari transmisi, refleksi atau emisi suatu iluminator dari berbagai sudut. Perbedaan mendasar antara perangkat tomografi yang satu dengan yang lainnya adalah jenis iluminator yang digunakan dalam rangka memperoleh citra penampang melintang (tomogram), diantaranya sinar-X, netron, cahaya tampak, ultrasound, listrik, dan medan magnet.
Keunggulan penggunaan cahaya untuk menghasilkan citra tomografi, diantaranya adalah tidak memiliki efek ionisasi pada objek dan mampu menjalar pada jaringan biologis dengan mudah, walaupun dengan intensitas cahaya yang kuat [1]. Oleh karena itu, DOT ramai dikembangkan pada aplikasi medis dan non-medis. Salah satu pengembangan pada bidang non-medis adalah identifikasi kualitas produk pertanian pascapanen. Beberapa penelitian yang terkait adalah deteksi cacat internal pada kentang dan identifikasi fertilitas suatu telur [2,3].

Pada makalah ini, kami melakukan simulasi numerik untuk menganalisis efek zat pewarna pada buah terhadap sensitifitas citra penampang melintang buah berbasis Fluoresens DOT (FDOT). Hal ini dilakukan karena zat pewarna pada buah yang bersifat fluoresens, yaitu menyerap cahaya yang ditembakan oleh laser diode kemudian diemisikan kembali (cahaya emisi), mampu menambah informasi dari kondisi objek. Salah satu informasi yang mampu 


\section{Seminar Nasional Material 2013 | Fisika - Institut Teknologi Bandung}

direpresentasikan berdasarkan konsentrasi zat pewarna adalah tingkat kematangan buah (informasi fungsional, contoh: semangka, markisa, delima, labu dan sawo).

Makalah ini terdiri dari empat bab, bab pertama berisi pendahuluan. Bab kedua menjelaskan mengenai prinsip DOT, sifat fluoresen, FDOT, penjalaran cahaya dan metode elemen hingga (MEH). Sedangkan bab ketiga dan terakhir berisi mengenai analisi dan kesimpulan dari hasil simulasi numerik.

\section{TEORI DASAR}

Tomografi optik adalah teknik rekonstruksi citra yang berdasarkan pada pola perambatan cahaya yang ditembakan oleh sumber, yang kemudian diserap, ditansmisikan, dihamburkan dan/atau diemisikan oleh medium objek, dimana cahaya tersebut kemudian diukur intensitas keluarannya pada permukaan objek, seperti yang ditunjukan pada Gambar 1. Cahaya tersebut akan membawa informasi mengenai koefisien optik yang terkandung di dalam objek.

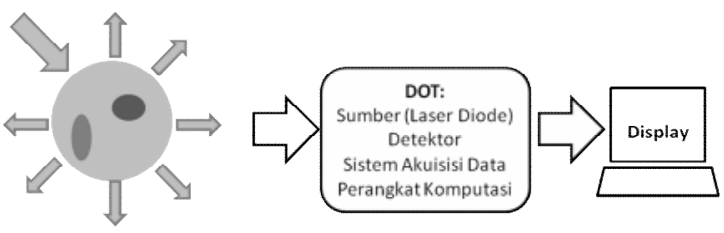

Gambar 1 Skema Perangkat DOT

Ketika cahaya inframerah-dekat diluminasikan ke permukaan objek dan bertransmisi melewati zat pewarna yang bersifat fluoresen, maka zat tersebut akan menyerap sebagian intensitas cahaya datang kemudian mengemisikannya kembali, seperti yang diperlihatkan pada Gambar 2. Oleh karena itu, pada simulasi ini konsentrasi zat pewarna yang terkandung di dalam buah diperhitungkan untuk menambah informasi mengenai kondisi bagian dalam buah.

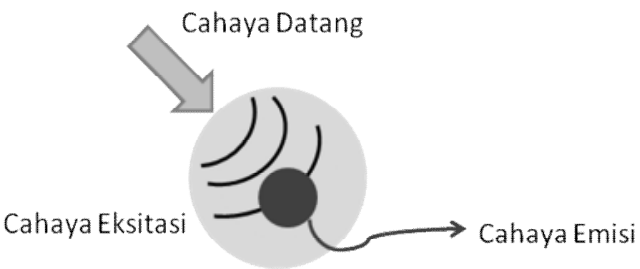

Gambar 2. Zat Fluoresens

Terdapat tiga metode pengolahan sinyal yang umum digunakan pada sistem DOT, yaitu domain kondisi tunak, domain waktu, dan domain frekuensi[4]. Pada simulasi kali ini digunakan pendekatan gelombang kontinu, yaitu sistem domain berada pada kondisi tunak, hanya dilakukan analisis terhadap atenuasi intensitas cahaya setelah melalui sebuah medium.

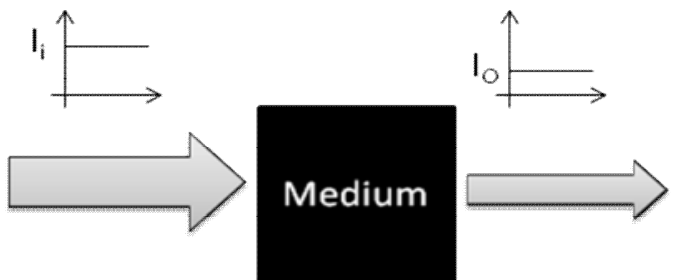

Gambar 3. Atenuasi intensitas cahaya saat melewati medium yang berada pada kondisi tunak

Proses propagasi cahaya pada keadaan tunak yang mengalami hamburan, penyerapan dan emisi pada sebuah medium seperti jaringan dapat didekati dengan menggunakan persamaan Boltzmann sebagai berikut:

$$
\begin{aligned}
& {\left[-\nabla \cdot D(r) \nabla+\mu_{a}(r)+\varepsilon N(r)\right] \Phi_{x}(r)=q_{x}(r)} \\
& {\left[-\nabla \cdot D(r) \nabla+\mu_{a}(r)+\varepsilon N(r)\right] \Phi_{m}^{*}(r)=\gamma \varepsilon N(r) \Phi_{x}(r)}
\end{aligned}
$$

Dengan $r$ [mm] adalah posisi, $\Phi\left[\mathrm{W} / \mathrm{mm}^{2}\right]$ adalah Intensitas cahaya di dalam volume $\Omega, q\left[\mathrm{~W} / \mathrm{mm}^{3}\right]$ adalah sumber cahaya di dalam medium, $D[\mathrm{~mm}]$ adalah koefisien difusi optik yang merupakan representasi dari $1 /\left(3 \mu_{s}{ }^{\prime}\right)$ dimana $\mu_{s}{ }^{\prime}\left[\mathrm{mm}^{-1}\right]$ koefisien

redusi hamburan (reduced scattering), $\mu_{a} \quad\left[\mathrm{~mm}^{-1}\right]$

koefisien absorbsi, $\varepsilon\left[\mu \mathrm{M}^{-1} \mathrm{~mm}^{-1}\right]$ koefisien molar zat pewarna, $N(r)$ konsntrasi zat fluoresens, $\gamma$ quantum yield fluoresens, $x$ menunjukan properti cahaya datang sedangkan $m$ adalah properti cahaya emisi[5].

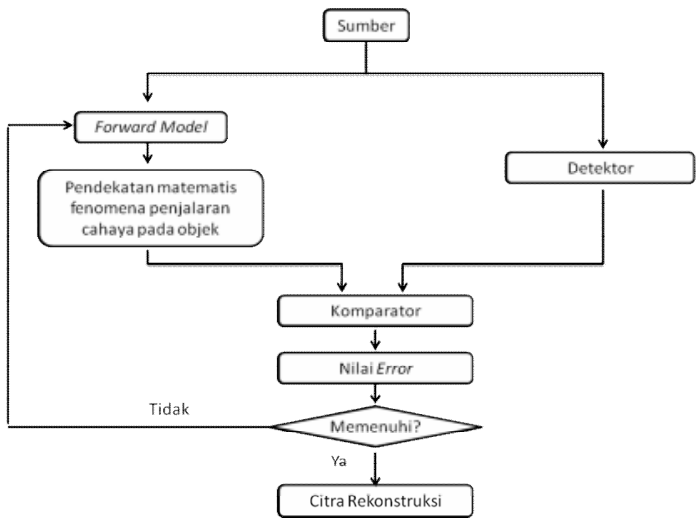

Gambar 4. Skema algoritma rekonstruksi citra DOT secara umum 


\section{Seminar Nasional Material 2013 | Fisika - Institut Teknologi Bandung}

Proses rekonstruksi citra DOT, yang diperlihatkan pada Gambar 4 menunjukan bahwa hasil estimasi yang diperoleh dari simulasi dengan menggunakan masalah maju akan dibandingkan dengan intensitas hasil pengukuran dan menghasilkan fungsi objektif. Apabila fungsi objektif masih lebih besar dari batas toleransi, maka matriks estimasi distrubusi koefisien optik akan dikoreksi. Matriks distribusi koefisien optik yang telah dikoreksi digunakan untuk menentukan estimasi intensitas permukaan, yang kemudian dibandingkan terhadap intensitas hasil pengukuran. Proses tersebut terus diulang hingga konvergensi fungsi objektif dicapai [6].

Pada pengerjaan simulasi ini model maju (forward model) yang digunakan adalah pemodelan $\mathrm{MEH}$ (metode elemen hingga) dengan elemen berbentuk segitiga. MEH merupakan metode permodelan numerik untuk mencari solusi pendekatan persamaan diferensial parsial dan juga persamaan integral. FEM bekerja dengan cara mencacah suatu objek menjadi domain yang lebih sederhana (dalam simulasi ini adalah segitiga). Dengan mencacah domain objek menjadi domain yang lebih sederhana, persamaan pendekatan yang diperlukan dapat dibuat lebih sistematis dalam sebuah pendekatan variasi dari solusi sebuah masalah melalui setiap elemen segitiga. Segitiga-segitiga kecil tersebut membentuk cacahan dan masing-masing ujungnya disebut simpul (node) seperti yang diperlihatkan pada Gambar 5.

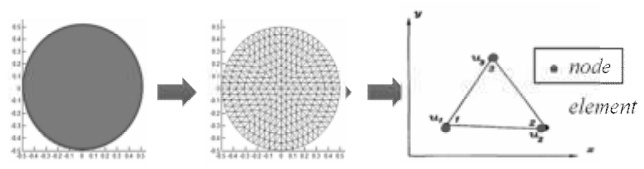

Gambar 5. Pendekatan objek dengan menggunakan $\mathrm{MEH}$ elemen segitiga

Dengan MEH solusi pendekatan menjadi lebih sederhana karena perhitungan diterapkan pada masingmasing segitiga yang ada sehingga proses evaluasi menjadi lebih mudah, selain itu pendekatan dengan menggunakan persamaan polinomial menjadi lebih mudah dalam domain yang lebih kecil. Untuk memperoleh solusi persamaan dalam domain besar dapat didekati dengan menggunakan persamaan linear pada segitiga-segitiga yang bersebelahan.

Pada MEH, kerapatan foton $\Phi$ didekati dengan fungsi kontinu $\Phi^{\mathrm{h}}$ sebanyak $\mathrm{N}$ fungsi linear $\mathrm{u}_{\mathrm{j}}$, yang dapat dinyatakan sebagai berikut.

$$
\Phi^{h}(r)=\sum_{j=1}^{N} \Phi_{j} u_{j}(r)
$$

Jika $r$ berada dalam domain $\Omega$, dan $\partial \Omega$ adalah kondisi batas, kita dapat menggunakan persamaan
Galerkin untuk mendapatkan solusi $\Phi$ sehingga untuk untuk semua $\mathrm{r} \in \Omega$ maka

$\int_{\Omega} u_{i}(r)\left[\left\{-\nabla . D(r) \nabla+\mu_{a}(r)\right\} \Phi_{x}(r)-q_{o}(r)\right] d \Omega=0$

dimana $u$ adalah fungsi coba. Jika persamaan II.3 terpenuhi untuk semua $u$ maka persamaan II.2 harus terpenuhi untuk semua $r$ dalam domain $\Omega$.

\section{RANCANGAN SIMULASI}

Simulasi ini dirancang untuk menganalisis efek dari zat pewarna yang bersifat fluoresens. Pada simulasi ini digunakan 12 detektor dan 12 sumber, seperti yang diperlihatkan pada Gambar 6 .

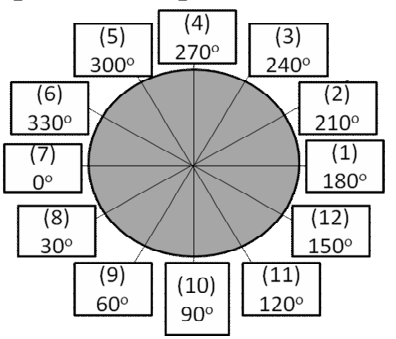

Gambar 6. Posisi penempatan detektor dan sumber cahaya

Sistem kerja simulasi yang dirancang adalah apabila sumber nomor 1 menyala maka detektor yang aktif adalah detektor nomor 2-12 dst. Terdapat dua rancangan simulasi. Pada simulai pertama rancangan objek yang disimulasikan merepresentasikan penyebaran zat pewarna yang terkandung di dalam semangka, dimana diasumsikan bahwa semangka memiliki kandungan zat pewarna yang semakin tinggi ke arah pusat. Gambar 7 merupakan objek simulasi yang merepresentasikan buah semangka.

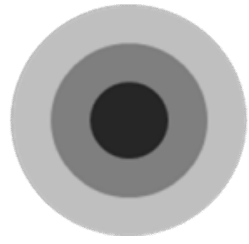

Gambar 7. Rancangan objek simulasi 1 yang merepresentasikan buah semangka

Sedangkan pada simulasi kedua, rancangan objek yang digunakan merepresentasikan penyebaran konsentrasi zat pewarna pada buah manggis, yaitu zat pewarna hanya terkonsentrasi dibagian kulit. Objek tersebut ditunjukan pada Gambar 8. 


\section{Seminar Nasional Material 2013 | Fisika - Institut Teknologi Bandung}

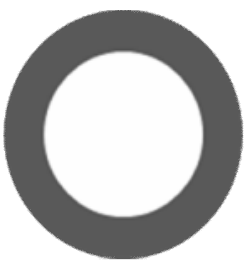

Gambar 8. Rancangan objek simulasi 2 yang merepresentasikan buah manggis

Untuk menganalisis efek zat pewarna terhadap sensitifitas kedua rancangan objek simulasi, maka dilakukan pembandingan antara hasil simulasi yang hanya memperhitungkan propagasi cahaya terhadap koefisien serapan dan hamburan (A) dengan hasil simulasi yang memperhitungan kandungan zat pewarna pada objek (B).

\section{HASIL DAN ANALISIS}

Pada bab ini dipaparkan mengenai hasil simulasi metode elemem hingga 1A, 1B, 2A dan 2B.
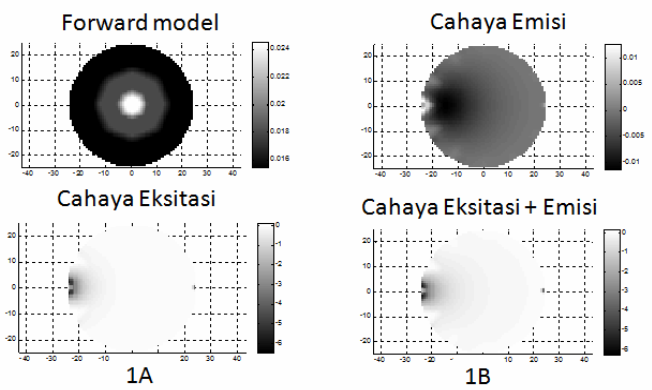

Gambar 9. Perbandingan antara objek MEH dan sebaran potensial cahaya antara $1 \mathrm{~A}$ dan $1 \mathrm{~B}$

Gambar 9 menunjukan potensial dari simulasi yang merepresentasikan penyebaran zat pewarna pada semangka. Dapat dilihat bahwa forward model menggambarkan konsentrasi zat pewarna pada semangka. Dari gambar tersebut dapat dilihat bahwa terjadi perubahan pada sebaran potensial cahaya dari kondisi A menjadi B, dimana pada kondisi B potensial cahaya yang digambarkan mengandung informasi cahaya emisi yang dihasilkan dari zat pewarna. Hal serupa dapat dilihat pula pada hasil simulasi $2 \mathrm{~A}$ dan 2 B yang diperlhatkan pada Gambar 10 .
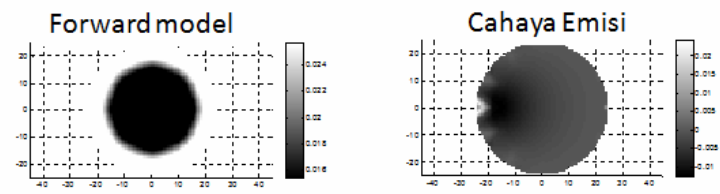

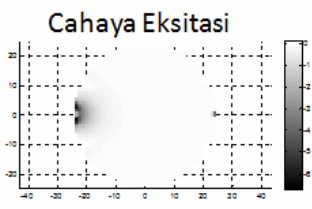

$2 \mathrm{~A}$

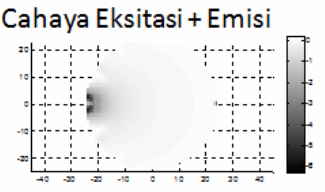

$2 \mathrm{~B}$
Gambar 10. Perbandingan antara objek MEH dan sebaran potensial cahaya antara $2 \mathrm{~A}$ dan $2 \mathrm{~B}$

Untuk dapat menganalisis perubahan yang terjadi akibat cahaya emisi dari zat pewarna, maka nilai intensitas yang dideteksi oleh detektor pada kondisi 1A, 1B, 2A dan 2B dibandingkan menggunakan grafik sbb:

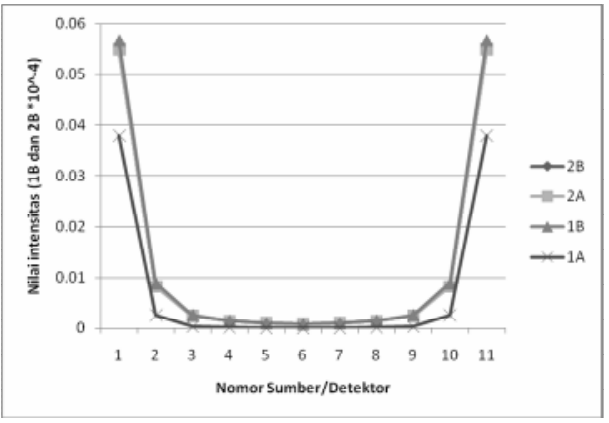

Grafik 1. Perbandingan profil intensitas pada bidang batas antara $1 \mathrm{~A}, 1 \mathrm{~B}, 2 \mathrm{~A}$ dan 2B

Dari Grafik 1 terlihat bahwa profil intensitas cahaya antara simulasi yang memperhitungkan efek emisi cahaya dari zat pewarna (B) cenderung lebih tinggi dibanding perhitungan potensial cahaya tanpa perhitungan efek emisi zat pewarna (A). Untuk mempertegas hasil analisis tersebut dilakukan perhitungan statistik berupa nilai rata-rata cahaya intensitas di bidang batas. Hasil dari perhitungan nilai rata-rata intensitas tersebut dilampirkan pada Tabel 1 .

TABEL 1. Perbandingan Nilai Rata-rata Intensitas

\begin{tabular}{lcc}
\hline \multicolumn{1}{c}{ Simulasi } & A & B \\
\hline Semangka & 0,015094 & 0,021845 \\
Manggis & 0,012821 & 0,021216 \\
\hline
\end{tabular}

Berdasarkan Tabel 1 dapat ditarik kesimpulan bahwa nilai rata-rata intensitas pada bidang batas dari kedua simulai mengalami peningkatan apabila efek cahaya emisi dari zat pewarna yang terkandung didalam buah diperhitungkan dalam simulasi. Untuk 


\section{Seminar Nasional Material 2013 | Fisika - Institut Teknologi Bandung}

penelitian selanjutnya, peneliti akan memvalidasi hasil simulasi ini dengam hasil percobaan di laboratorium.

\section{REFERENSI}

1. K. Tahir, Optical Tomography, www.imperial.ac.uk/research/photonics/ research/ topics/tomog/tomog.htm, 3 April 2012.

2. E. Kate K, H. S. Tapp, Richard B, Robert O. M and Anthony J.P (2008) : Feasibility study of NIR diffuse optical tomography on agricultural produce, Science Direct, Postharvest Biology and Technology.

3. M. Panayiotou, A. Gibson dan Prof. J. Hebden (2005) : 3Dimensional Optical Tomography of an Unfertilised Chicken Egg, Thesis, Medical Physics, University College London.

4. S. Keren, O. Gheysens, C. S. Levin and S. S. Gambhir (2008), A Comparison Between a Time Domain and Continuous wave Small Animal Optical Imaging System, IEEE Medical Imaging .

5. Marjono, A. Yano, S. Okawa, F. Gao, and Y. Yamada (2008) : Total light approachof time domain fluorescence diffuse optical Tomography, Optics Express, 16, 1310413121, 2008.

6. J. Ripoll and V. Ntziachristos (2003) : Iterative boundary method for diffuse optical tomography, Journal of the Optical Society of America, 20, 6. 